\title{
Research Advances in Antitumor Mechanism of Evodiamine
}

\author{
Luning Li $\mathbb{D}^{1},{ }^{1}$ Cunxin Zhang $\mathbb{D}^{2},{ }^{2}$ Chen Huang $\mathbb{D},{ }^{1}$ Xinchen Tian $\mathbb{D},{ }^{3}$ Wenxue Sun $\mathbb{D},{ }^{1,4}$ \\ and Shulong Jiang $\mathbb{D}^{1}$ \\ ${ }^{1}$ Tumor Laboratory, Jining No. 1 People's Hospital, Jining Medical University, Jining, Shandong 272000, China \\ ${ }^{2}$ Department of Spine Surgery, Jining No. 1 People's Hospital, Jining Medical University, Jining, Shandong 272000, China \\ ${ }^{3}$ Cheeloo College of Medicine, Shandong University, Jinan, Shandong 250100, China \\ ${ }^{4}$ Department of Pharmacy, Jining No. 1 People's Hospital, Jining Medical University, Jining, Shandong 272000, China
}

Correspondence should be addressed to Wenxue Sun; sunwenxue121@126.com and Shulong Jiang; jnsljiang@163.com

Received 4 October 2021; Revised 16 November 2021; Accepted 30 December 2021; Published 18 January 2022

Academic Editor: J.B. Heredia

Copyright (c) 2022 Luning Li et al. This is an open access article distributed under the Creative Commons Attribution License, which permits unrestricted use, distribution, and reproduction in any medium, provided the original work is properly cited.

\begin{abstract}
Evodiamine is a natural alkaloid extracted from Fructus Evodia. This bioactive alkaloid has been reported to have a wide range of biological activities, including anti-injury, antiobesity, vasodilator, and anti-inflammatory effects. In recent years, it has been found that evodiamine has tumor-suppressive effects on a variety of tumors. There is growing evidence that evodiamine can inhibit the rapid proliferation of tumor cells, induce cell cycle arrest at a certain phase, increase the incidence of apoptosis, promote autophagy, inhibit microangiogenesis and migration, and regulate immunotherapy. Evodiamine can inhibit Wnt/ $\beta$-catenin, mTOR, NF- $\kappa$ B, PI3K/AKT, JAK-STAT, and other signaling pathways in various cancer cells, and it can significantly downregulate the expression of many tumor markers, such as VEGF and COX-2. These facts partially explain the antitumor mechanism of evodiamine. In this article, the antitumor mechanism of evodiamine was reviewed to provide the basis for its clinical application and therapeutic development in the future.
\end{abstract}

\section{Introduction}

The traditional Chinese medicine Fructus Evodia is the dry fruit of the plant Evodia rutaecarpa, and it was first mentioned in "Shennong Materia Medica Classic." It has been found that E. rutaecarpa has analgesic, antidiarrheal, antiemetic, and antiinflammatory effects in clinical practice [1-5]. The dried, powdered fruit $(2.5 \mathrm{~kg})$ of $E$. rutaecarpa was defatted with n-hexane $(2 \times 5 \mathrm{~L})$ and extracted with acetone $(3 \times 5 \mathrm{~L})$ at room temperature to yield an extract $(137 \mathrm{~g})$. The crude acetone extract was then eluted with $n$-hexane: acetone $(9: 1-19: 1)$ on a silica gel column to produce evodiamine $(6.17 \mathrm{~g})$ [6]. Evodiamine was also purified from Fructus Evodia by a highperformance liquid chromatography method with a gradient elution of acetonitrile-tetrahydrofuran- $0.02 \%$ phosphoric acid at the detection wavelength of $220 \mathrm{~nm}[7,8]$.

Previous studies have shown that evodiamine has many biological activities, including anti-inflammation [9-14], antiobesity [12], analgesia [14], and promotion of vasodilation [15-18]. These activities are related to a wide range of targets, such as caspase 3 and transient receptor potential vanilloid 1
(TRPV1) [19-22]. In recent years, evodiamine has been found to have antitumor activity against a variety of tumor cells, involving various mechanisms that cause cancer cell death, such as induction of cell cycle arrest, promotion of cell apoptosis, promotion of autophagy, and inhibition of tumor invasion and metastasis [23-30] (Figure 1). The signaling pathways involved in the antitumor effect of evodiamine include the classical apoptosis pathway, endoplasmic reticulum stress, MAPK, PI3K-Akt, and JAK-STAT [31-34]. In this article, the antitumor mechanism of evodiamine was reviewed based on research trends in recent years, and the ways through which evodiamine could exert its antitumor effect were summarized to provide a basis for its clinical application and in-depth research.

\section{Molecular Mechanisms of Antitumor Effect of Evodiamine}

2.1. Inhibition of Tumor Cell Proliferation and Cell Cycle. There is evidence that evodiamine reduces the occurrence of tumors by inhibiting the proliferation of cancer cells and changing the cell cycle. Previous studies have shown that 


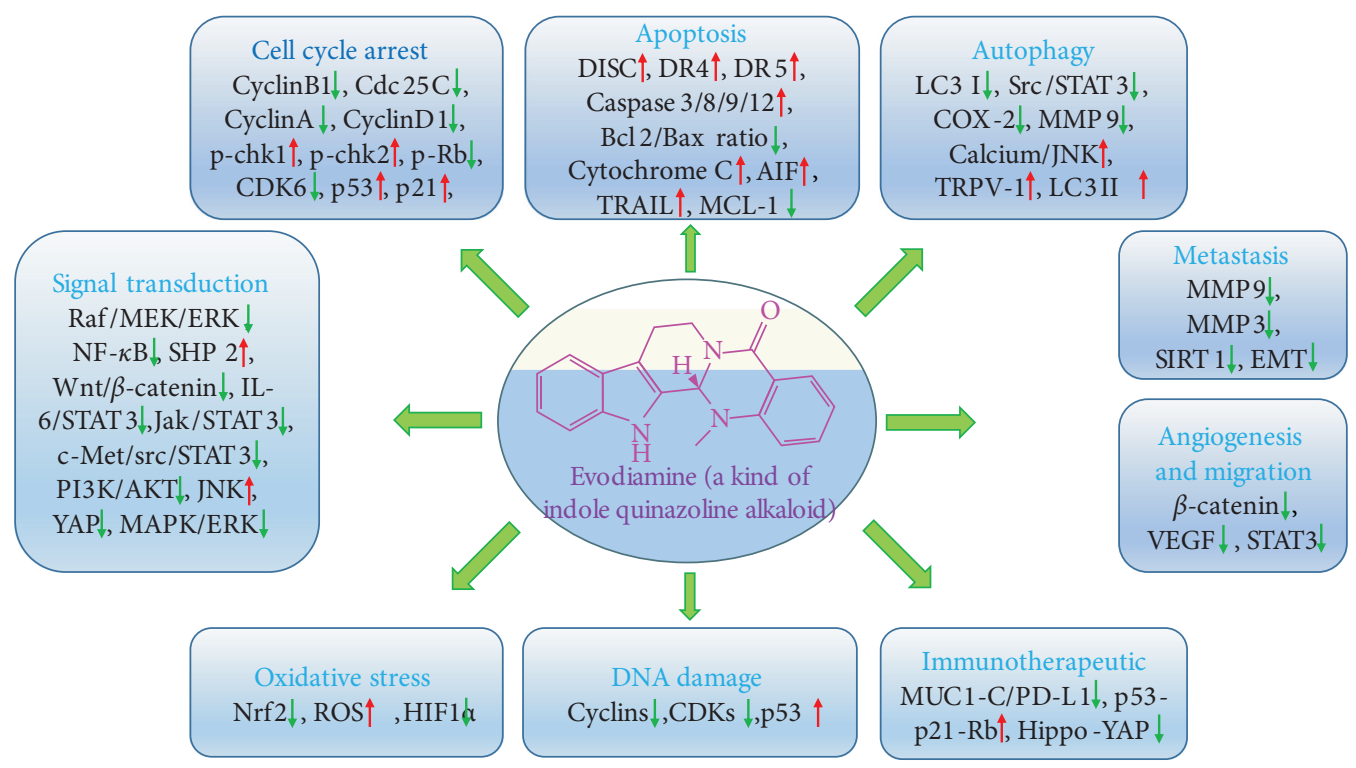

FIgURE 1: Synopsis of the multifactorial mode of action of evodiamine-type drugs.

evodiamine can inhibit the proliferation of human cancer cell lines, such as breast cancer [35], colon cancer [36], liver cancer [37, 38], cholangiocarcinoma [27], osteosarcoma [39], and melanoma [40] in a dose- and time-dependent manner (Table 1). One of the distinguishing features of tumor cells is their dysregulation of the cell cycle caused by the abnormal expression of cyclins and/or the abnormal replication of DNA. The activity and expression states of CDC25 C, cyclin, and cyclin-dependent kinases (CDKs) regulate the stability of the cell cycle. Many studies have shown that arresting tumor cell cycle progression is an effective strategy to inhibit tumor proliferation [41-45].

Previous studies have reported that evodiamine may block the cell cycle progression and significantly increase the percentage of G2/M phase cells in tumors (Table 2). Zhou et al. found that evodiamine affected the cell cycle progression in human osteosarcoma cells U2OS. The same authors reported that the expression levels of cyclin B1, CDC25 C, and CDC2 changed significantly, which may be related to evodiamine-dependent downregulation of the phosphorylation of MEK and ERK and inhibition of the Raf/ MEK/ERK signaling pathway [46]. Moreover, in human lung cancer cells with G2/M phase arrest after evodiamine treatment, cyclin A and cyclin B1 expression levels decreased, whereas those of $\mathrm{p}$-Chk1 and $\mathrm{p}$-Chk2 increased [47]. In addition, evodiamine interferes with the colorectal cancer cell lines COLO205 and HT-29, causing the cell cycle to stagnate in the G2/M phase, which has been shown to be related to changes in cyclin $\mathrm{B} 1 / \mathrm{CDC} 25 \mathrm{C}$ expression and is controlled by JNK [48]. According to the above studies, evodiamine induces the G2/M cycle arrest by affecting signaling factors involved in multiple signaling pathways regulating cyclins, CDKs, and $\mathrm{CHK}$.

Evodiamine may also cause some tumor cells to stagnate at the G0/G1 phase (Table 2). Interestingly, Du et al. found evidence of evodiamine-induced downregulation of cyclin D1 and CDK6 in human breast cancer MDA-MB-231 cells; these cells stagnated at the G0/G1 phase in the presence of evodiamine treatment [49]. In another study, after using evodiamine, the cells were seeded in the upper well of a Transwell and incubated with $10 \mu \mathrm{g} / \mathrm{mL}$ PGI/AMF and $10 \mu \mathrm{g} / \mathrm{mL}$ PGI/AMF $+6 \mu \mathrm{mol} / \mathrm{L}$ evodiamine for $28 \mathrm{~h}$. Normal cells served as the control group. We then used these cells to treat human breast cancer MCF-7 and MDA-MB-231 cells, and tumor cells were arrested at the G0/G1 phase; p53 and p21 were upregulated; and p-Rb, cyclin B, and cyclin A were downregulated [50]. Based on these results, evodiamine keeps the cell cycle in the G0/G1 phase by targeting the p53$\mathrm{p} 21-\mathrm{Rb}$ signaling pathway and affecting the expression of G0/G1 phase cyclin-related proteins.

2.2. Promotion of Apoptosis in Tumor Cells. Apoptosis is a very important and highly conservative cell death model that can effectively inhibit tumorigenesis. The classical process of cell apoptosis involves caspases as the core proteins that activate other proenzymes in a sequence, which involves multiple signaling pathways leading to cellular apoptosis [51-55]. The promotion effects of evodiamine on apoptosis signal transduction pathways can be divided into extrinsic and intrinsic categories. The extrinsic pathway involves the activation of the death receptor pathway, whereas the intrinsic pathway includes the activation of the mitochondrial and endoplasmic reticulum pathways.

Evodiamine induces the expression of death receptors on the surface of tumor cells and promotes the binding of death receptors to their ligands, thereby accelerating the formation of DISC and leading to apoptosis (Table 3). According to Khan et al., evodiamine can upregulate the death receptors DR4 and DR5 in U87 glioblastoma cells under the synergistic effect of tumor necrosis factor-related apoptosis-inducing ligand (TRAIL), which leads to the activation of caspases 3 and 8 and the induction of apoptosis in tumor cells [56]. 
TABLE 1: Inhibition of tumor cell activity and proliferation by evodiamine in cancer cell lines.

\begin{tabular}{|c|c|c|c|c|}
\hline Cell line & Cell type & Specific results & Mode of action & References \\
\hline MCF-7/ADR & Breast cancer & $\begin{array}{c}\text { The } \mathrm{IC}_{50} \text { values of MCF-7 cells treated with } \\
\text { evodiamine for } 24,48 \text {, and } 72 \mathrm{~h} \text { were } 7.68 \mu \mathrm{M} \text {, } \\
0.64 \mu \mathrm{M} \text {, and } 0.30 \mu \mathrm{M} \text {, respectively. The } \mathrm{IC}_{50} \text { values } \\
\text { of the MCF-7/ADR cells were higher than those of } \\
\mathrm{MCF}-7 \text {, with values of } 24.47 \mu \mathrm{M}, 1.26 \mu \mathrm{M} \text {, and } \\
0.47 \mu \mathrm{M} \text { for } 24,48 \text {, and } 72 \mathrm{~h} \text { of treatment with } \\
\text { evodiamine, respectively. }\end{array}$ & $\begin{array}{l}\text { Inhibiting cell activity via the } \\
\text { regulation of Ras/MEK/ERK } \\
\text { pathway }\end{array}$ & {$[35]$} \\
\hline $\begin{array}{l}\text { HCT-116/L- } \\
\text { OHP }\end{array}$ & Colorectal cancer & $\begin{array}{l}\text { The cells were treated with evodiamine at } 0.4,0.8 \text {, } \\
\text { and } 1.6 \mu \mathrm{M} \text { for } 24,48 \text {, and } 72 \mathrm{~h} \text {, respectively. } \\
\text { Evodiamine significantly enhanced rhodamine } 123 \\
\text { accumulation and caused a significant decrease in } \\
\text { the } \mathrm{IC}_{50} \text { level in HCT-116/L-OHP cells. }\end{array}$ & $\begin{array}{l}\text { Inhibiting the p50/p65 NF- } \\
\text { kappaB pathway }\end{array}$ & {$[36]$} \\
\hline $\begin{array}{l}\text { HepG2, Huh- } \\
7 \text {, and Hep3B }\end{array}$ & $\begin{array}{l}\text { Hepatocellular } \\
\text { carcinoma }\end{array}$ & $\begin{array}{l}\text { The cells were treated with evodiamine at } 0.25,0.5 \text {, } \\
1,2,4,6 \text {, and } 8 \mu \mathrm{M} \text { for } 72 \mathrm{~h} \text {. Evodiamine inhibited } \\
\text { the proliferation of HCC cells in a dose-dependent } \\
\text { manner under hypoxia (survival fraction: } 1.0-0.3 \text { ). }\end{array}$ & $\begin{array}{l}\text { Downregulating HIF-1 } \alpha \text { under } \\
\text { hypoxia }\end{array}$ & {$[37]$} \\
\hline $\begin{array}{l}\text { HepG2 and } \\
\text { Bel-7402 }\end{array}$ & $\begin{array}{l}\text { Hepatocellular } \\
\text { carcinoma }\end{array}$ & $\begin{array}{c}\text { Evodiamine treatment at a range of concentrations } \\
(0,0.25,1,4,8,16 \text {, and } 32 \mu \mathrm{M}) \text { inhibited HepG } 2 \\
\text { cells and Bel-7402 growth. The } \mathrm{IC}_{50} \text { values of } \\
\text { HepG2 and Bel-7402 cells at } 48 \mathrm{~h} \text { were } 14.7 \mu \mathrm{M} \text { and } \\
16 \mu \mathrm{M} \text {, respectively. }\end{array}$ & $\begin{array}{l}\text { Affecting the Hippo-Yes- } \\
\text { associated protein signaling } \\
\text { pathway }\end{array}$ & {$[38]$} \\
\hline $\begin{array}{l}\text { HuCCT-1 and } \\
\text { TFK-1 }\end{array}$ & Cholangiocarcinoma & $\begin{array}{c}\text { Two CCA cell lines, HuCCT- } 1 \text { and TFK- } 1 \text {, were } \\
\text { treated with evodiamine at different concentrations } \\
(0,5,10,20 \text {, or } 40 \mu \mathrm{M}) \text { for different time periods } \\
(24,48 \text {, or } 72 \text { h). Cell viability: } 80 \%-20 \% \text { (HuCCT- } \\
1) ; 75 \%-25 \% \text { (TFK- } 1) .\end{array}$ & $\begin{array}{l}\text { Inducing IL-6/STAT3 signaling } \\
\text { inhibition. }\end{array}$ & {$[27]$} \\
\hline $\begin{array}{l}143 B \text { and } \\
\text { MG63 }\end{array}$ & Osteosarcoma & $\begin{array}{l}143 \mathrm{~B} \text { cells were treated with evodiamine at } 0.5,1,2 \text {, } \\
4,6,8,16 \text {, and } 32 \mu \mathrm{M} . \mathrm{MG} 63 \text { cells were treated with } \\
\text { evodiamine at } 0.25,0.5,1,2,4,6,8 \text {, and } 16 \mu \mathrm{M} \text {. Cell } \\
\text { viability was measured at } 24,48 \text {, and } 72 \mathrm{~h} \text {. Relative } \\
\text { growth rate: } 95 \%-15 \%(143 \mathrm{~B}) ; 98 \%-30 \% \text { (MG63). }\end{array}$ & $\begin{array}{l}\text { Inhibiting Wnt/beta-catenin } \\
\text { signaling pathway }\end{array}$ & [39] \\
\hline A-375 & Melanoma & $\begin{array}{l}\text { The cells were treated with evodiamine at } 5,7.5,10 \text {, } \\
12.5 \text {, and } 15 \mu \mathrm{M} \text { for } 24,48 \text {, and } 72 \mathrm{~h} \text {. Relative cell } \\
\text { viability: } 1.0-0.2 \text {. }\end{array}$ & $\begin{array}{l}\text { Inducing reactive oxygen } \\
\text { species-dependent apoptosis } \\
\text { and necrosis }\end{array}$ & {$[40]$} \\
\hline
\end{tabular}

TABLE 2: Induction of cell cycle arrest by evodiamine in cancer cell lines in vitro.

\begin{tabular}{|c|c|c|c|c|}
\hline Cell line & Cell type & Specific results & Mode of action & References \\
\hline $\mathrm{U} 2 \mathrm{OS}$ & Osteosarcoma & $\begin{array}{c}\text { Evodiamine treatment at a range of concentrations } \\
(0,3,6 \text {, and } 12 \mu \mathrm{M}) \text { triggered } \mathrm{G} 2 / \mathrm{M} \text { cell cycle arrest } \\
(9 \%-77 \%) \text { for } 24 \mathrm{~h} .\end{array}$ & $\begin{array}{l}\text { Inhibiting the Raf/MEK/ERK } \\
\text { signaling pathway }\end{array}$ & [46] \\
\hline A549 & Lung cancer & $\begin{array}{l}\text { Evodiamine treatment at a range of concentrations } \\
(0,1,2 \text {, and } 4 \mu \mathrm{M}) \text { triggered } \mathrm{G} 2 / \mathrm{M} \text { cell cycle arrest } \\
(15.8 \%-86.2 \%) \text { for } 24 \mathrm{~h} .\end{array}$ & Downregulation of ERK & [47] \\
\hline $\begin{array}{l}\text { COLO205 and } \\
\text { HT-29 }\end{array}$ & $\begin{array}{l}\text { Colorectal } \\
\text { carcinoma }\end{array}$ & $\begin{array}{l}\text { Evodiamine treatment at a range of concentrations } \\
(0,1,2 \text {, and } 4 \mu \mathrm{M}) \text { triggered } \mathrm{G} 2 / \mathrm{M} \text { cell cycle arrest for } \\
24 \mathrm{~h} \text {; evodiamine treatment at } 2 \mu \mathrm{M} \text { triggered } \mathrm{G} 2 / \mathrm{M} \\
\text { cell cycle arrest for } 6,12 \text {, and } 24 \mathrm{~h} \text {. }\end{array}$ & JNK activation & [48] \\
\hline MDA-MB-231 & Breast cancer & $\begin{array}{c}\text { Exposure to different concentrations of evodiamine } \\
(0,15,30,60,90 \text {, and } 120 \mu \mathrm{M}) \text { caused G0/G1 arrest of } \\
\text { MDA-MB-231 }(53.29 \%-60.12 \%) \text { for } 24 \mathrm{~h} \text {. }\end{array}$ & $\begin{array}{l}\text { Decreasing Bcl-2, cyclin D1, and } \\
\text { cyclin-dependent kinase } 6 \\
\text { expression }\end{array}$ & [49] \\
\hline $\begin{array}{l}\text { MCF-7 and } \\
\text { MDA-MB-231 }\end{array}$ & Breast cancer & $\begin{array}{l}\text { Cell cycle analyses in monolayer culture (condition } \\
\text { with FBS, without FBS), sphere culture condition. } \\
\text { Evodiamine }(0,100 \text {, and } 200 \mathrm{nM} \text { ) mildly but } \\
\text { significantly increased the proportion of cells at the } \\
\text { G1 stage. }\end{array}$ & $\begin{array}{l}\text { Activating the p53-p21-Rb } \\
\text { pathway }\end{array}$ & [50] \\
\hline
\end{tabular}

Evodiamine can transform the tumor cells' mitochondrial membrane into a state of increased permeability, thereby causing the irreversible release of various apoptosis promoters, including cytochrome $\mathrm{C}$ and $\mathrm{AIF}$, into the cytoplasm or the nucleus and promoting the occurrence of apoptosis (Table 3). Mohan et al. found that evodiamine 
TABLE 3: Induction of apoptosis and autophagy by evodiamine in cancer cell lines in vitro.

\begin{tabular}{|c|c|c|c|c|}
\hline Cell line & Cell type & Specific results & Mode of action & References \\
\hline U87 & Glioblastoma & $\begin{array}{l}\text { The cells were treated with evodiamine }(10 \mu \mathrm{M}) \text { and } \\
\text { TRAIL }(50 \mathrm{ng} / \mathrm{ml}) \text { either separately or in combination } \\
\text { for } 24 \mathrm{~h} \text {. TRAIL alone did not induce apoptosis, } \\
\text { whereas evodiamine significantly induced apoptosis in } \\
\text { U87 glioblastoma cells after } 24 \mathrm{~h} \text { (apoptosis rate: } 35 \% \text { - } \\
70 \%) \text {. }\end{array}$ & $\begin{array}{l}\text { Sensitizing cells to TRAIL via the } \\
\text { death receptor pathway }\end{array}$ & {$[56]$} \\
\hline $\begin{array}{l}\text { A549 and } \\
\text { H1299 }\end{array}$ & $\begin{array}{l}\text { Lung epithelial } \\
\text { cancer }\end{array}$ & $\begin{array}{c}\text { Evodiamine }(20-40 \mu \mathrm{M}) \text { treatment of A549 cells for } \\
24 \text { h significantly increased the number of apoptotic } \\
\text { cells by sixfold. }\end{array}$ & $\begin{array}{l}\text { Activating both the intrinsic and } \\
\text { the extrinsic apoptosis pathways }\end{array}$ & {$[57]$} \\
\hline U937 & Leukemia & $\begin{array}{l}\text { The cells were treated with evodiamine }(0.2-0.8 \mu \mathrm{mol} / \\
\mathrm{L}) \text { for } 18 \mathrm{~h} \text {. Evodiamine induced apoptosis in a dose- } \\
\text { dependent manner (sub-G1 population: } 5 \%-45 \%) \text {. }\end{array}$ & $\begin{array}{l}\text { Activating caspase-dependent } \\
\text { and caspase-independent } \\
\text { pathways }\end{array}$ & {$[58]$} \\
\hline $\begin{array}{l}\text { MC3 and } \\
\text { HSC4 }\end{array}$ & Oral cancer & $\begin{array}{c}\text { The cells were treated with various concentrations of } \\
\text { evodiamine }(0.25,0.5 \text {, and } 1 \mu \mathrm{M} \text { for MC3 cells; and } 0.2 \text {, } \\
2 \text {, and } 20 \mu \mathrm{M} \text { for HSC } 4 \text { cells) for } 24 \mathrm{~h} \text {. The apoptotic } \\
\text { effect of evodiamine was confirmed by } 4^{\prime}-6- \\
\text { diamidino-2-phenylindole (DAPI) staining. } \\
\text { Evodiamine-treated cells displayed nuclear } \\
\text { condensation and fragmentation-hallmarks of } \\
\text { apoptosis. }\end{array}$ & Inhibiting the AKT pathway & {$[59]$} \\
\hline $\begin{array}{l}\text { H446 and } \\
\text { H1688 }\end{array}$ & $\begin{array}{l}\text { Small cell lung } \\
\text { cancer }\end{array}$ & $\begin{array}{l}\text { The induction of apoptosis was detected in } \mathrm{H} 446 \text { or } \\
\text { H1688 cells after } 24 \mathrm{~h} \text { of treatment with } 10 \mu \mathrm{M} \\
\text { evodiamine. The apoptosis rate of evodiamine-treated } \\
\mathrm{H} 446(\sim 15 \%) \text { or H1688 }(\sim 11 \%) \text { cells was much higher } \\
\text { than that of the untreated cells (blank control, } \sim 5 \% \text { or } \\
\qquad 4 \%) .\end{array}$ & $\begin{array}{l}\text { Activating mitochondria- } \\
\text { dependent and endoplasmic } \\
\text { reticulum stress-induced } \\
\text { pathways }\end{array}$ & {$[60]$} \\
\hline U87-MG & Glioblastomas & $\begin{array}{c}\text { The percentage of autophagy induced by evodiamine } \\
(0,0.1,6,10 \mu \mathrm{M}) \text { increased to a maximum at } 24 \mathrm{~h} \text {, but } \\
\text { not at } 48 \mathrm{~h} \text {, indicating that evodiamine-induced } \\
\text { autophagy in a dual-regulated manner. }\end{array}$ & $\begin{array}{l}\text { Activating calcium/c-Jun } \mathrm{N}- \\
\text { terminal kinase and calcium/ } \\
\text { mitochondria-mediated } \\
\text { pathways }\end{array}$ & {$[61,62]$} \\
\hline $\begin{array}{l}\text { Panc-1 and } \\
\text { SW1990 }\end{array}$ & $\begin{array}{l}\text { Pancreatic } \\
\text { cancer }\end{array}$ & $\begin{array}{l}\text { PANC-1 and SW } 1990 \text { cells were treated with } \\
\text { evodiamine }(1.0,5.0 \text {, and } 10 \mu \mathrm{M}) \text { for } 48 \mathrm{~h} \text {. The } \\
\text { exposure of cells to evodiamine led to a dose- } \\
\text { dependent increase in apoptosis. Apoptosis rate: } 2.5 \%- \\
\text { 17.5\% (Panc- } 1) ; 4 \%-18 \% \text { (SW1990). }\end{array}$ & $\begin{array}{l}\text { Inhibiting the PI3K-Akt and the } \\
\text { MAPK/ERK signaling pathways }\end{array}$ & {$[63]$} \\
\hline $\begin{array}{l}\text { Murine Lewis } \\
\text { lung } \\
\text { carcinoma }\end{array}$ & Lung carcinoma & $\begin{array}{l}\text { The cells exhibited an increase in MDC fluorescence } \\
\text { within } 1.5-6 \mathrm{~h} \text { after evodiamine treatment, while the } \\
\text { peak of autophagy activity was observed in } 1.5 \mathrm{~h} \\
\text { treatment. In addition, evodiamine-treated cells } \\
\text { displayed a greater number of distinct spots within the } \\
\text { cytoplasm or perinuclear regions compared with } \\
\text { controls. }\end{array}$ & $\begin{array}{l}\text { Activating caspase-independent } \\
\text { pathways }\end{array}$ & {$[64]$} \\
\hline
\end{tabular}

significantly increased the mitochondrial membrane depolarization, increased the cell apoptosis rate, and slightly decreased the Bcl-2/Bax ratio in human lung cancer A549 and H1299 cells. It also increased the release of cytochrome $\mathrm{C}$ from mitochondria into the cytoplasm, thereby activating the cascade of proapoptotic pathways, including caspases 3 and 9 [57]. In another study, evodiamine was found to promote the mitochondrial release of AIF into the nucleus in human leukemia U937 cells, leading to chromosome agglutination and the induction of cellular apoptosis [58]. In addition, evodiamine can also promote mitochondrial apoptosis of tumor cells by suppressing the expression of the inhibitor of apoptosis proteins. Mcl-1 is an apoptosis inhibitor protein located on the mitochondrial membrane. Sachita et al. found that evodiamine reduced the expression of Mcl-1 during transcriptional modification, and knockout of Mcl-1 significantly increased the expression of active Bax, thereby inducing apoptosis [59]. These studies have shown that evodiamine can effectively regulate the ratio of proapoptotic and antiapoptotic factors to promote changes in mitochondrial membrane that are conducive to apoptosis and promote the occurrence of mitochondria-dependent apoptosis.

Endoplasmic reticulum stress occurs when proteins are disrupted during transport from the endoplasmic reticulum (ER) to the Golgi apparatus. When newly synthesized or when the $\mathrm{Ca}^{2+}$ equilibrium state is broken, unfolded or misfolded proteins accumulate in large quantities in the ER. Fang et al. treated human small cell lung cancer H446 and H1688 cells with evodiamine and found excessive accumulation of reactive oxygen species (ROS), which caused endoplasmic reticulum stress and released a large amount of 
$\mathrm{Ca}^{2+}$. Furthermore, the upregulation of caspase- 12 led to the upregulation of caspase- 9 and caspase- 3 expression, which in turn led to apoptosis [60]. Therefore, evodiamine can disrupt the $\mathrm{Ca}^{2+}$ balance in cells and induce ER stress by activating caspase- 12 and other signaling pathways, thereby activating the ER-mediated apoptosis pathway (Table 3).

\subsection{Induction of Autophagy of Tumor Cells. Autophagy is a} process of lysosome phagocytosis and degradation of its own structure, which can remove damaged cellular structures and senile organelles. This process exists in most eukaryotic cells [65-67]. Autophagosome formation and processing of microtubule-associated protein 1 light 3 (LC3) are two major signs of autophagy.

The role of autophagy in tumors is controversial. In fact, it may play different roles at different stages of tumor genesis and development [68-73]. Evodiamine induces protective autophagy mediated by the activation of the JNK pathway following extracellular $\mathrm{Ca}^{2+}$ influx. Liu et al. found that evodiamine could induce autophagy in human glioblastoma U87-MG cells. The application of an extracellular calcium scavenger and an antagonist of transient receptor potential vanillin-1 (TRPV-1) reduced the percentage of cells undergoing autophagy. The same phenomenon was confirmed by knocking down the expression of TRPV-1 by small-interfering RNA technology. Moreover, the activation of c-Junn terminal kinase (JNK) by evodiamine was decreased by the TRPV1 antagonist, which further confirmed that evodiamine can promote autophagy through the $\mathrm{Ca}^{2+}$ mediated JNK pathway [61].

Although there have been many reports that evodiamine can promote autophagy in tumors, some studies have shown that evodiamine-related induction of autophagy in specific cells antagonizes apoptosis. This observation illustrates the complexity of the antitumor mechanism of evodiamine. Hong et al. found that evodiamine-induced apoptosis of prostate cancer (PC) cells by inhibiting the PI3K-Akt and MAPK/ERK signaling pathways in human pancreatic cancer Panc-1 and SW1990 cells, and by inhibiting the phosphorylation of signal transduction and transcriptional activator 3 to inhibit autophagy [63]. Tu et al. found that evodiamine could improve the expression level of the autophagy-specific genes (Atgs) in Lewis lung cancer cells, accelerate the transformation from LC3-I to LC3-II, and thus promote the formation of autophagosomes (Table 3). Moreover, when combined with the autophagy inhibitor 3-methyladenine (3-MA), autophagy induced by evodiamine was significantly reduced, while apoptosis was increased. This suggests that autophagy induced by evodiamine may have a protective effect on tumor cells and that the inhibition of autophagy can promote the occurrence of apoptosis [64]. Liu et al. further found that evodiamine could induce autophagy mediated by calcium/JNK signals in glioma cells, while treatment with $\mathrm{Ca}^{2+}$ scavenger BAPTA-AM significantly inhibited the activation of the intracellular JNK pathway and decreased autophagy, while apoptosis was increased [62]. These results confirm that evodiamine can promote $\mathrm{Ca}^{2+}$-mediated autophagy in the JNK pathway and that the inhibition of autophagy induced by this pathway can reduce the activity of tumor cells and promote apoptosis.

\subsection{Inhibition of Tumor Microangiogenesis and Tumor} Migration. Vascular endothelial growth factor (VEGF), one of the most important growth factors, plays a key role in promoting angiogenesis (Table 4). It can promote mitosis and has antiapoptotic effect on endothelial cells; moreover, it increases vascular permeability and promotes cell migration. Because of these effects, VEGF actively regulates the angiogenesis of normal and pathological blood vessels [78-80]. VEGF and VEGF receptors (VEGFRs) are expressed on both endothelial and nonendothelial cells [81, 82]. Currently, the use of anti-VEGF and anti-VEGF receptor therapies to block angiogenesis in cancer or other pathological processes is considered extremely important.

Hepatocellular carcinoma (HCC) is a highly vascularized tumor, with high microvascular density and high levels of circulating VEGF. Shi et al. found that after the intervention with evodiamine in the subcutaneous $\mathrm{H} 22$ cell xenograft model, tumor growth was inhibited, and serum tumor markers, $\beta$-catenin, and VEGFa levels were significantly reduced. Evodiamine also blocked angiogenesis in the matrigel plug assay by inhibiting VEGF. In addition, evodiamine inhibited tumor growth and reduced the expression levels of various angiogenesis biomarkers, $\beta$-catenin, and VEGFa in the SMMC-7721 HCC cell xenograft model. Evodiamine was shown to have an antitumor effect on HCCs by inhibiting $\beta$-catenin, interacting with VEGFa, and reducing VEGFa expression, thereby inhibiting angiogenesis [74]. These results suggest that evodiamine can inhibit cell invasion and migration, block angiogenesis, and act as a potential therapeutic agent for HCC.

Signal transduction and activator of transcription (STAT) is activated in many human tumor cell lines and primary tumors. STAT3 plays an important role in angiogenesis in the tumor microenvironment and can regulate the expression of VEGF, matrix metallopeptidases (MMP), and other factors [83-86]. Hwang et al. found that treatment with evodiamine in PC-3 and DU145 cells significantly inhibited cell proliferation, reduced HGF-regulated c-Met/ Src/STAT3 phosphorylation, and disrupted nuclear transfer of STAT3 protein. That study also revealed that evodiamine downregulated the expression of several carcinogenic markers, including COX-2, VEGF, and MMP-9. In addition, reduced Src/STAT3 activation was observed in PC-3 and DU145 cells transfected with c-Met small-interfering RNA (siRNA), resulting in reduced evodiamine-induced apoptosis [75] (Table 4). These results indicate that evodiamine can markedly inhibit the activation of the c-Met/Src/STAT3 signaling pathway, thereby inhibiting tumor cell survival, proliferation, and angiogenesis.

Metastasis is one of the main hazards and characteristics of malignant tumors, and is a key factor affecting the prognosis and survival status of patients. Matrix metalloproteinases are a large class of zinc-containing endopeptidases that have important biological functions in 
TABLE 4: Inhibition of microangiogenesis and migration by evodiamine in cancer cell lines in vitro or in vivo.

\begin{tabular}{|c|c|c|c|c|}
\hline Cell line & $\begin{array}{l}\text { Cell type/animal } \\
\text { models }\end{array}$ & Specific results & Mode of action & References \\
\hline
\end{tabular}

(1) To evaluate the effect of evodiamine on VEGFinduced angiogenesis, Matrigel plug assays were performed with C57BL/6 mice. The addition of evodiamine $(200 \mu \mathrm{g})$ to the plugs containing HepG2, Hepatocellular VEGF inhibited vascular formation. These plugs SMMC-7721, carcinoma BALB/c displayed a paler appearance, and fewer blood $\mathrm{H} 22 \quad$ nude mice vessels were observed.

Inhibiting $\beta$-catenin and reducing VEGFa expression

(2) HepG2 cells and SMMC-7721 cells were exposed to $0,5,10$, or $20 \mu \mathrm{mol} / \mathrm{L}$ of evodiamine for $24 \mathrm{~h}$. Representative images of cell migration and invasion were assessed with Transwells.

PC-3 and DU145 cells were treated with $5 \mu \mathrm{M}$ evodiamine for 24, 36, and $48 \mathrm{~h}$. Evodiamine substantially downregulated the expression of VEGF.

PC-3 and $\quad$ Prostate cancer
DU145

HT-29 and Colorectal cancer HCT-116 BALB/c nude mice

HCT-116 Colorectal cancer

\section{Inhibiting the c-Met/Src/STAT3} signaling pathway
Inactivating the JAK2/STAT3 pathway through the downregulation of PGI

After treatment with different concentrations of evodiamine $(0$ or $1.5 \mu \mathrm{mol} / \mathrm{L})$ for $24 \mathrm{~h}$, the migration rates were detected. Wound-healing assay showed that treatment with evodiamine $(1.5 \mu \mathrm{mol} / \mathrm{L})$ significantly repressed the migration of HT-29 cells and HCT-116 cells.

Migration potential was assessed by Transwell assay after the cells had been treated by agents.

The cells were seeded in the upper well of a Transwell insert, incubated with $10 \mu \mathrm{g} / \mathrm{mL}$ PGI/ AMF and with $10 \mu \mathrm{g} / \mathrm{mL}$ PGI/AMF $+6 \mu \mathrm{mol} / \mathrm{L}$ evodiamine for $28 \mathrm{~h}$. Normal cells served as the control group. Evodiamine significantly inhibited

PGI-induced migration in HCT-116 cells. various events, including metastasis of cancer cells [87-90]. Zhou et al. found that evodiamine inhibited the expression of MMP-9 in vitro and in vivo by inhibiting the acetyl-NF$\kappa \mathrm{B}$ p65 subunit induced by Sirt1 in colorectal cancer HT-29 and HCT-116 cells, and thus inhibited the invasion and metastasis of the tumor cells [76]. Zhao et al. also found that evodiamine inactivated the JAK2/STAT3 signaling pathway by downregulating the expression of phosphoglucose isomerase (PGI), thereby downregulating the expression of MMP3 to inhibit the migration of human colorectal cancer HCT-116 cells [77] (Table 4). According to these studies, evodiamine has a significant inhibitory effect on MMPs, the key regulatory enzymes essential for tumor migration, which makes it suitable for further study as a lead compound for the inhibition of tumor migration.

2.5. Antitumor Immunotherapeutic Mechanism of Evodiamine. Inhibitory receptors, such as cytotoxic T lymphocyte-associated protein 4 (CTLA4) and programmed cell death protein 1 (PD-1), play crucial roles in the inactivation of immune cells in the tumor microenvironment. The activation, amplification, and effector function of CD8+ T cells are significantly inhibited by the interaction between PD-1 and programmed death ligand 1 (PD-L1), which also assists in the immune escape of cancer cells [91-93]. In addition, the interaction between the microenvironment and immune regulation plays a critical role in clinical treatment. It is widely believed that activated CD8+ T cells have anticancer immunity in a variety of tumors and have a significant positive prognostic effect. Furthermore, the survival status of cancer patients is significantly affected by tumor-infiltrating CD8+ lymphocytes (TILs) in the tumor environment, further supporting the strong link between immune escape and the tumor microenvironment [94]. MUC1-C is highly expressed in a variety of tumor cells and regulates a variety of genes, including PD-L1, that are important for the immune escape of tumor cells. Jiang et al. found that, after acting on non-small cell lung cancer cells, evodiamine downregulated the expression of the MUC1-C/ PD-L1 signaling pathway at both the transcription and protein levels, reduced the apoptosis of T cells, and significantly increased the level of CD8+ T cells. Evodiamine may therefore be a potential targeted therapy suitable as an adjuvant for immunotherapy [94] (Table 5). By acting on PD-L1 and other inhibitors that suppress T-cell activation, evodiamine improves the tumor microenvironment, increases the activation level of CD8+ T cells, and effectively inhibits immune escape, which has the potential to promote the efficacy of immunotherapy.

2.6. Other Effects of Evodiamine. In recent years, the development of antitumor drugs has focused on the development of bioactive molecules that can effectively and selectively act on a single molecular target. However, due to the complexity 
TABLe 5: Antitumor immunotherapeutic mechanisms and antitumor drug combinations involving evodiamine.

\begin{tabular}{|c|c|c|c|c|}
\hline Cell line & $\begin{array}{l}\text { Cell type/animal } \\
\text { models }\end{array}$ & Specific results & Mode of action & References \\
\hline $\begin{array}{l}\text { H1650 and } \\
\text { H1975 }\end{array}$ & $\begin{array}{l}\text { Non-small cell lung } \\
\text { cancer }\end{array}$ & $\begin{array}{l}\text { Evodiamine }(0,2,4,8,16 \mu \mathrm{M} ; 24 \mathrm{~h}) \text { suppressed } \\
\text { IFN- } \gamma \text {-induced PD-L1 expression in H1975 and } \\
\text { H1650 cells. MUC1-C mRNA and protein } \\
\text { expression were decreased by evodiamine }(0,2,4 \text {, } \\
8,16 \mu \mathrm{M} ; 24 \mathrm{~h}) \text { in NSCLC cells as well. } \\
\text { Evodiamine }(0,2,4,8,16 \mu \mathrm{M} ; 24 \mathrm{~h}) \\
\text { downregulated the PD-L1 expression and } \\
\text { diminished the apoptosis of T cells. It inhibited } \\
\text { MUC1-C expression and potentiated CD8+ T-cell } \\
\text { effector function. }\end{array}$ & $\begin{array}{c}\text { Elevating CD8+ T cells and } \\
\text { downregulating the MUC1-C/PD- } \\
\text { L1 signaling pathway }\end{array}$ & {$[94]$} \\
\hline $\begin{array}{l}\text { A } 549, \mathrm{H} 460, \\
\mathrm{H} 1299 \text {, and } \\
\mathrm{H} 1650\end{array}$ & $\begin{array}{l}\text { Non-small cell lung } \\
\text { cancer }\end{array}$ & $\begin{array}{l}\text { The cells were treated with evodiamine }(3 \mu \mathrm{M}) \text {, } \\
\text { erlotinib }(20 \mu \mathrm{M}) \text {, or the combination for } 48 \mathrm{~h} \text {. } \\
\text { Combining evodiamine with erlotinib } \\
\text { successfully inhibited cell proliferation and } \\
\text { survival in wild-type EGFR NSCLC cells, } \\
\text { characterized as erlotinib-resistant. In addition, } \\
\text { evodiamine plus erlotinib significantly increased } \\
\text { the apoptotic rate }(61.86 \%) \text { of NSCLC cells, as } \\
\text { compared to single-agent treatment alone } \\
\text { (evodiamine } \sim 33.71 \% \text {; erlotinib } \sim 21.92 \%) \text {. }\end{array}$ & $\begin{array}{l}\text { mTOR/S6K1- mediated } \\
\text { downregulation of Mcl-1 }\end{array}$ & [95] \\
\hline $\begin{array}{l}\text { Caco-2 and } \\
\text { HT-29 }\end{array}$ & $\begin{array}{c}\text { Colorectal } \\
\text { adenocarcinoma }\end{array}$ & $\begin{array}{l}\text { Evodiamine }(10 \mu \mathrm{M}) \text { enhanced the effect of } \\
\text { berberine }(0,2.5,5,10,20,40 \mu \mathrm{M}) \text { on cell viability } \\
\text { with } \mathrm{IC}_{50} \text { values ranging from } 38.85 \mu \mathrm{M} \text { to } \\
15.82 \mu \mathrm{M} \text { in Caco- } 2 \text { cells at } 24 \mathrm{~h} \text {, but evodiamine } \\
\text { did not have this effect in HT- } 29 \text { cells. }\end{array}$ & $\begin{array}{l}\text { Attenuating the overexpression of } \\
\text { P-gp gene }\end{array}$ & {$[96]$} \\
\hline
\end{tabular}

of various regulatory mechanisms in tumor cells, it is difficult for many single-target drugs to achieve lasting and effective control of tumors in the actual development process [97-100]. Therefore, the use of drug combinations is an advanced way to overcome these limitations.

$\mathrm{Li}$ et al. found that evodiamine combined with erlotinib can successfully inhibit the proliferation and survival of wildtype EGFR non-small cell lung cancer (NSCLC) cells with erlotinib resistance. Furthermore, the combination of evodiamine and erlotinib promoted apoptosis in NSCLC cells more significantly than any single-dose therapy. That study suggested that the combination of evodiamine and erlotinib may downregulate the expression of MCL-1 by regulating the mTOR/S6K1 pathway. Thus, evodiamine can significantly increase the sensitivity of tumor cells to erlotinib, and the combination of erlotinib and evodiamine could be an alternative solution for the problem of erlotinib resistance [95] (Table 5). In addition, chemotherapy can lead to inevitable side effects. Guan et al. found that evodiamine significantly inhibited the overexpression of the p-glycoprotein gene of P-glycoprotein-positive colorectal cancer cells through the synergistic effect with berberine, thus achieving an excellent anticancer effect. However, this synergistic effect was not associated with cell cycle arrest and apoptosis. The same study found that the synergistic effect of evodiamine and berberine also reduced the cardiotoxicity caused by evodiamine, which was closely related to berberine's regulation of exogenous apoptosis in NRF2-dependent and ROS-independent pathways. Therefore, the combination regimen of berberine and evodiamine is considered to have a better antitumor effect, while it significantly reduces side effects by targeting specific cells [96] (Table 5). The above research provides strong evidence for the effects of evodiamine in antitumor combination drugs and further supports the rationality of its application in tumor chemotherapy.

2.7. Structure-Activity Analysis of the Effects of Evodiamine-Related Compounds on the Antitumor Mechanism of Evodiamine. Structure-activity analysis of evodiamine, evodiamine-2, evodiamine-4, evodiamine-7, evodiamine-8, and evodiamine-12 showed that these compounds have the ability to induce DNA ladder formation in some cell lines. The results showed that adding an alkyl group, such as methyl or butyl, to the 14th position of quinazoline was essential for evodiamine to induce apoptosis [48]. According to another report, the researchers performed docking and molecular dynamics simulations on the homology model of TRPV1 to better understand the possible binding mode of evodiamine in the TRPV1 binding pocket [101]. The pharmacodynamic gene model further provided confidence in the effectiveness of docking research. This study revealed for the first time the structural determinants required for the interaction between TRPV1 and evodiamine, and provided new suggestions for the rational design of new TRPV1 ligands.

Evodiamine has a free amine group with a medium molecular weight, which is easily converted into active derivatives with medicinal properties [102]. This structure, with a free $\mathrm{N}-\mathrm{H}$ group and a scaffold with a molecular weight of approximately 350 , can be included in structure-based virtual screening (SBVS) studies. In addition, evodiamine shares an "L-shaped" conformation at the active site of the topo1-DNA 


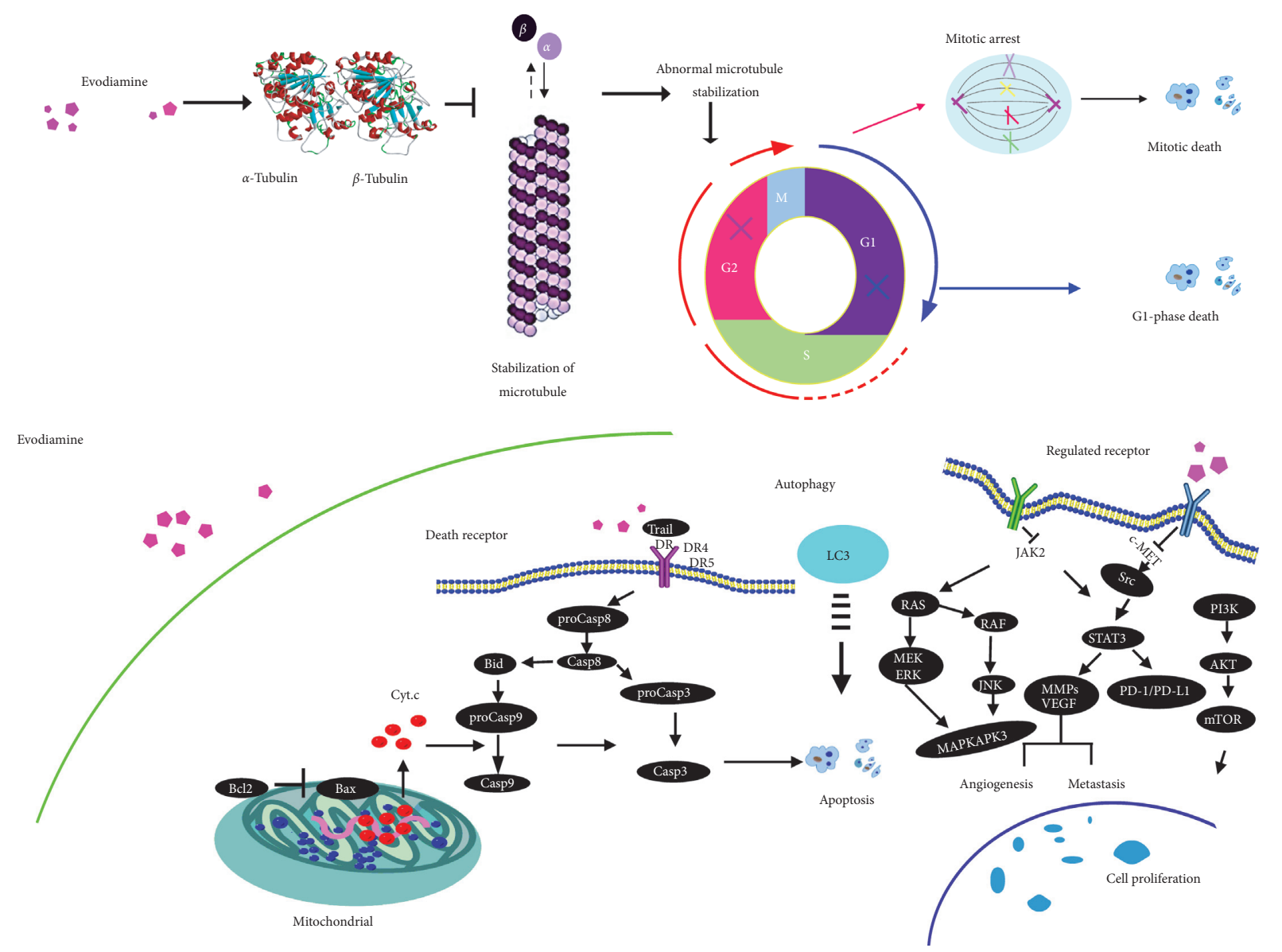

Figure 2: Probable molecular mechanisms by which evodiamine kills tumor cells.

cleavable complex. Its free indole N-H function is a suitable site for chemical derivatization. Proper functional group transformation to maintain hydrogen bond interaction is an effective method to maintain the binding affinity. When indoleamine is transferred to the amide, its carbonyl group can also form a hydrogen bond with Arg364. In this way, the key N-H group of evodiamine can undergo further chemical reactions and can be converted into active derivatives.

2.8. Cardiovascular Side Effects of Evodiamine. The effects of evodiamine on primary cultured neonatal rat cardiomyocytes have been studied in vitro, and the effects of evodiamine on zebrafish have been studied in vivo [103]. In vitro experiments have shown that evodiamine at a concentration of $28.44 \mu \mathrm{g} /$ $\mathrm{mL}$ cocultured with cells for $24 \mathrm{~h}$ resulted in a $50 \%$ inhibition rate of cell viability. In vivo results have shown that evodiamine at a concentration of $354 \mathrm{ng} / \mathrm{mL}$ caused cardiac dysfunction. These findings suggest that cardiac function should be monitored during evodiamine therapy.

\section{Conclusions and Prospects}

In recent years, a large number of experiments in vivo and in vitro have shown that evodiamine can inhibit the activity, proliferation, and cell cycle progression in various tumor cells. Evodiamine also promotes apoptosis and induces autophagy in tumor cells, inhibits the formation and migration of tumor microvessels, and participates in the regulation of tumor immunotherapy. In addition, several signaling pathways are modulated by evodiamine, including $\mathrm{PI} 3 \mathrm{~K} / \mathrm{Akt}$, mTOR, and NF- $\kappa \mathrm{B}$ cascades. Moreover, the excellent effect of the combination of other anticancer drugs with evodiamine in antitumor studies has further indicated its value for medicinal development (Figure 2).

It is predicted that efforts in using evodiamine as a multitarget antitumor drug in the following studies will be directed as follows. Its solubility, stability, and bioavailability need to be further improved so that it can exert its biological activity to a greater extent and more efficiently while reducing adverse reactions. In addition, further studies on the antitumor mechanism of evodiamine need to be conducted. For example, Src nonreceptor tyrosine kinases are important oncogenes that play an important role as an intermediate hub for phosphorylation and regulation of a variety of cytoplasmic downstream signals. In addition, STAT family transcriptional coactivators are important targets of Src. Furthermore, Src mediates the regulatory effects of extracellular signals on cell proliferation, migration, and apoptosis by participating in the transduction of various cellular signaling pathways. Current studies have shown that evodiamine interacts with the c-Met/Src/STAT3 signaling 
pathway and inhibits tumor cell angiogenesis. However, the molecular target characteristics of its interaction with upstream Src need to be further studied. In addition, the existing experimental results are still limited to in vitro cell and in vivo animal experiments. The lack of clinical research reports related to evodiamine and the adverse reactions to evodiamine need to be further studied in depth.[103]

\section{Abbreviations}

TRPV- Transient receptor potential vanillin-1

1 :

HIF- Hypoxia inducible factor- $1 \alpha$

$1 \alpha$ :

ROS: $\quad$ Reactive oxygen species

TRAIL: Tumor necrosis factor-related apoptosis-inducing ligand

JNK: c-Junn terminal kinase

VEGF: Vascular endothelial growth factor

STAT: Signal transduction and activator of transcription

MMP: Matrix metallopeptidases

CTLA4: Cytotoxic T lymphocyte-associated protein 4

PD-1: $\quad$ Programmed cell death protein 1

PD-L1: Programmed death ligand 1.

\section{Data Availability}

The datasets used in this study are available from the corresponding author upon reasonable request.

\section{Conflicts of Interest}

The authors declare that they have no conflicts of interest.

\section{Authors' Contributions}

Wenxue Sun and Shulong Jiang contributed to the conception of the review. Luning $\mathrm{Li}$ and Cunxin Zhang wrote the manuscript with support from Wenxue Sun and Shulong Jiang. Chen Huang and Xinchen Tian collected the literature. All authors have read and approved the final version of the manuscript. Luning Li and Cunxin Zhang contributed equally to this work.

\section{Acknowledgments}

This work was supported in part by the National Natural Science Foundation of China (Grant nos. 81873249 and 82074360) and the Doctoral Fund of Jining No. 1 People's Hospital (Grant nos. 2020006 and 2021-BS-008). The authors thank LetPub (https://www.letpub.com) for its linguistic assistance during the preparation of this manuscript.

\section{References}

[1] D. W. Li, M. Zhang, L. Feng et al., "Alkaloids from the nearly ripe fruits of Evodia rutaecarpa and their bioactivities," Fitoterapia, vol. 146, Article ID 104668, 2020.

[2] K. M. Tian, J. J. Li, and S. W. Xu, "Rutaecarpine: a promising cardiovascular protective alkaloid from Evodia rutaecarpa
(Wu Zhu Yu)," Pharmacological Research, vol. 141, p. 541, 2019.

[3] X. Cao, Y. Liu, M. Wang, L. Sun, and X. Ren, "Study on the source and characteristics of Evodia rutaecarpa based on chemical pattern recognition," Natural Product Research, vol. 33, p. 2113, 2019.

[4] X. L. Su, S. Xu, Y. Shan et al., "Three new quinazolines from Evodia rutaecarpa and their biological activity," Fitoterapia, vol. 127, p. 186, 2018.

[5] L. Yan, Q. F. Li, Y. T. Rong et al., "The protective effects of rutaecarpine on acute pancreatitis," Oncology Letters, vol. 15, p. 3121, 2018.

[6] N. Shoj, A. Umeyama, T. Takemoto, A. Kajiwara, and Y. Ohizumi, "Isolation of evodiamine, a powerful cardiotonic principle, from Evodia rufaecarpa bentham (rutaceae)," Journal of Pharmaceutical Sciences, vol. 75, Article ID 612613, 1986.

[7] Q. Fang, S. Jiang, and C. Li, “Evodiamine selectively inhibits multiple myeloma cell growth by triggering activation of intrinsic apoptosis pathway," OncoTargets and Therapy, vol. 12, Article ID 11383, 2019

[8] X. L. Tang, Z. Huang, Y. Chen et al., "Simultaneous determination of six bioactive compounds in evodiae Fructus by high-performance liquid chromatography with diode array detection," Journal of Chromatographic Science, vol. 52, Article ID 149156, 2014.

[9] X. Li, J. Ge, Q. Zheng, J. Zhang, R. Sun, and R. Liu, "Evodiamine and rutaecarpine from Tetradium ruticarpum in the treatment of liver diseases," Phytomedicine, vol. 68, Article ID 153180, 2020.

[10] X. Liu, X. Peng, and Z. Lin, "Evodiamine enhanced the antiinflammation effect of clindamycin in the BEAS-2B cells infected with $\mathrm{H} 5 \mathrm{~N} 1$ and pneumoniae D39 through CREB-C/ EBPbeta signaling pathway," Viral Immunology, vol. 34, 2021.

[11] M. Li and C. Wang, "Traditional uses, phytochemistry, pharmacology, pharmacokinetics and toxicology of the fruit of Tetradium ruticarpum: a review," Journal of Ethnopharmacology, vol. 263, Article ID 113231, 2020.

[12] J. Wei, L.-C. Ching, J.-F. Zhao et al., "Essential role of transient receptor potential vanilloid type 1 in evodiaminemediated protection against atherosclerosis," Acta Physiologica, vol. 207, p. 299, 2013.

[13] C. S. Shi, J.-M. Li, C.-C. Chin, Y.-H. Kuo, Y.-R. Lee, and Y.-C. Huang, "Evodiamine induces cell growth arrest, apoptosis and suppresses tumorigenesis in human urothelial cell carcinoma cells," Anticancer Research, vol. 37, p. 1149, 2017.

[14] Q. Lv, Y. Xue, G. Li et al., "Beneficial effects of evodiamine on P2X(4)-mediated inflammatory injury of human umbilical vein endothelial cells due to high glucose," International Immunopharmacology, vol. 28, p. 1044, 2015.

[15] Y. Wang, K. Kimura, K.-I. Inokuma et al., "Potential contribution of vasoconstriction to suppression of heat loss and homeothermic regulation in UCP1-deficient mice," Pflügers Archiv, vol. 452, p. 363, 2006.

[16] Z. Zhao, X. He, W. Han et al., "Genus Tetradium L.: a comprehensive review on traditional uses, phytochemistry, and pharmacological activities," Journal of Ethnopharmacology, vol. 231, p. 337, 2019.

[17] Y. Shi, Q. Hua, N. Li, M. Zhao, and Y. Cui, "Protective effects of evodiamine against LPS-induced acute kidney injury through regulation of ROS-NF-kappaB-mediated 
inflammation," Evidence-based Complementary and Alternative Medicine, vol. 2019, Article ID 2190847, 9 pages, 2019.

[18] C. Sun, G. Zhang, S. Luan et al., "Evodiamine inhibits the proliferation of leukemia cell line K562 by regulating peroxisome proliferators-activated receptor gamma (PPARgamma) pathway," Journal of Receptors and Signal Transduction Research, vol. 36, p. 422, 2016.

[19] X. Hu, R. Jiao, H. Li et al., "Antiproliferative hydrogen sulfide releasing evodiamine derivatives and their apoptosis inducing properties," European Journal of Medicinal Chemistry, vol. 151, p. 376, 2018.

[20] Q. Fang, S. Jiang, and C. Li, "Evodiamine selectively inhibits multiple myeloma cell growth by triggering activation of intrinsic apoptosis pathway," OncoTargets and Therapy, vol. 12, Article ID 11383, 2019.

[21] S. Negri, P. Faris, V. Rosti, M. R. Antognazza, F. Lodola, and F. Moccia, "Endothelial TRPV1 as an emerging molecular target to promote therapeutic angiogenesis," Cells-basel, vol. 9, 2020.

[22] S. Wang, S. Yamamoto, Y. Kogure, W. Zhang, K. Noguchi, and Y. Dai, "Partial activation and inhibition of TRPV1 channels by evodiamine and rutaecarpine, two major components of the fruits of Evodia rutaecarpa," Journal of Natural Products, vol. 79, p. 1225, 2016.

[23] M. Ogasawara, T. Matsunaga, S. Takahashi, I. Saiki, and H. Suzuki, "Anti-invasive and metastatic activities of evodiamine," Biological and Pharmaceutical Bulletin, vol. 25, p. 1491, 2002.

[24] H. Kim, Y. Yu, S. G. Choi et al., "Evodiamine eliminates colon cancer stem cells via suppressing notch and Wnt signaling," Molecules, vol. 24, 2019.

[25] D. Wang, S. Ge, Z. Chen, and Y. Song, "Evodiamine exerts anticancer effects via induction of apoptosis and autophagy and suppresses the migration and invasion of human colon cancer cells," Journal of B.U.ON.: Official Journal of the Balkan Union of Oncology, vol. 24, p. 1824, 2019.

[26] X. Yang, Y. Zhang, Y. Huang et al., "Evodiamine suppresses Notch3 signaling in lung tumorigenesis via direct binding to gamma-secretases," Phytomedicine, vol. 68, Article ID 153176, 2020.

[27] B. Zhu, L. Zhao, Y. Liu et al., "Induction of phosphatase shatterproof 2 by evodiamine suppresses the proliferation and invasion of human cholangiocarcinoma," The International Journal of Biochemistry \& Cell Biology, vol. 108, p. 98, 2019.

[28] D. Zeng, P. Zhou, R. Jiang et al., "Evodiamine inhibits vasculogenic mimicry in HCT116 cells by suppressing hypoxia-inducible factor 1-alpha-mediated angiogenesis," Anti-Cancer Drugs, vol. 32, p. 314, 2021.

[29] H. Yu, H. Jin, W. Gong, Z. Wang, and H. Liang, "Pharmacological actions of multi-target-directed evodiamine," Molecules, vol. 18, p. 1826, 2013.

[30] A. Rasul, B. Yu, L. Zhong, M. Khan, H. Yang, and T. Ma, "Cytotoxic effect of evodiamine in SGC-7901 human gastric adenocarcinoma cells via simultaneous induction of apoptosis and autophagy," Oncology Reports, vol. 27, p. 1481, 2012.

[31] R. Wang, D. Deng, N. Shao et al., "Evodiamine activates cellular apoptosis through suppressing PI3K/AKT and activating MAPK in glioma," OncoTargets and Therapy, vol. 11, p. 1183, 2018.

[32] C. S. Liu, T. Xia, Z.-Y. Luo et al., "Network pharmacology and pharmacokinetics integrated strategy to investigate the pharmacological mechanism of Xianglian pill on ulcerative colitis," Phytomedicine, vol. 82, Article ID 153458, 2021.

[33] W. S. Wu, C. C. Chien, Y. C. Chen, and W. T. Chiu, "Protein kinase RNA-like endoplasmic reticulum kinase-mediated bcl-2 protein phosphorylation contributes to evodiamineinduced apoptosis of human renal cell carcinoma cells," PLoS One, vol. 11, Article ID e160484, 2016.

[34] L. Wei, X. Jin, Z. Cao, and W. Li, "[Evodiamine induces extrinsic and intrinsic apoptosis of ovarian cancer cells via the mitogen-activated protein kinase/phosphatidylinositol3-kinase/protein kinase B signaling pathways]," Journal of Traditional Chinese Medicine, vol. 36, p. 353, 2016.

[35] S. Wang, L. Wang, Z. Shi, Z. Zhong, M. Chen, and Y. Wang, "Evodiamine synergizes with doxorubicin in the treatment of chemoresistant human breast cancer without inhibiting P-glycoprotein," PLoS One, vol. 9, Article ID e97512, 2014.

[36] H. Sui, L.-H. Zhou, Y.-L. Zhang et al., "Evodiamine suppresses ABCG2 mediated drug resistance by inhibiting p50/ p65 NF-kappaB pathway in colorectal cancer," Journal of Cellular Biochemistry, vol. 117, p. 1471, 2016.

[37] Y. L. Li, N.-Y. Zhang, X. Hu et al., "Evodiamine induces apoptosis and promotes hepatocellular carcinoma cell death induced by vorinostat via downregulating HIF-1alpha under hypoxia," Biochemical and Biophysical Research Communications, vol. 498, p. 481, 2018.

[38] S. Zhao, K. Xu, R. Jiang et al., "Evodiamine inhibits proliferation and promotes apoptosis of hepatocellular carcinoma cells via the Hippo-Yes-Associated Protein signaling pathway," Life Sciences, vol. 251, Article ID 117424, 2020.

[39] S. Yang, J. Chen, T. Tan et al., "Evodiamine exerts anticancer effects against 143B and MG63 cells through the wnt/betacatenin signaling pathway," Cancer Management and Research, vol. 12, p. $2875,2020$.

[40] N. Liu, Y. Li, G. Chen, and K. Ge, "Evodiamine induces reactive oxygen species-dependent apoptosis and necroptosis in human melanoma A-375 cells," Oncology Letters, vol. 20, p. 121, 2020.

[41] J. Chen, "The cell-cycle arrest and apoptotic functions of p53 in tumor initiation and progression," Cold Spring Harb Perspect Med, vol. 6, Article ID a26104, 2016.

[42] P. Strzyz, "Cell signalling: signalling to cell cycle arrest," Nature Reviews Molecular Cell Biology, vol. 17, p. 536, 2016.

[43] L. Zhao, X. Han, J. Lu, D. McEachern, and S. Wang, "A highly potent PROTAC androgen receptor (AR) degrader ARD-61 effectively inhibits AR-positive breast cancer cell growth in vitro and tumor growth in vivo," Neoplasia, vol. 22, p. 522, 2020.

[44] Y. T. Lee, S. H. Lim, B. Lee, I. Kang, and E. J. Yeo, "Compound C inhibits B16-F1 tumor growth in a syngeneic mouse model via the blockage of cell cycle progression and angiogenesis," Cancers (Basel), vol. 11, 2019.

[45] C. Fitzpatrick, M. F. Bendek, M. Briones et al., "Mitochondrial ncRNA targeting induces cell cycle arrest and tumor growth inhibition of MDA-MB-231 breast cancer cells through reduction of key cell cycle progression factors," Cell Death \& Disease, vol. 10, p. 423, 2019.

[46] Y. Zhou and J. Hu, "Evodiamine induces apoptosis, G2/M cell cycle arrest, and inhibition of cell migration and invasion in human osteosarcoma cells via Raf/MEK/ERK signalling pathway," Medical Science Monitor, vol. 24, p. 5874, 2018.

[47] J. Y. Hong, S. H. Park, H. Y. Min, H. J. Park, and S. K. Lee, "Anti-proliferative effects of evodiamine in human lung cancer cells," Journal of Cancer Prevention, vol. 19, pp. 7-13, 2014. 
[48] C. C. Chien, M.-S. Wu, S.-C. Shen et al., "Activation of JNK contributes to evodiamine-induced apoptosis and G2/M arrest in human colorectal carcinoma cells: a structure-activity study of evodiamine," PLoS One, vol. 9, Article ID e99729, 2014.

[49] J. Du, X.-F. Wang, Q.-M. Zhou et al., "Evodiamine induces apoptosis and inhibits metastasis in MDAMB-231 human breast cancer cells in vitro and in vivo," Oncology Reports, vol. 30, p. 685, 2013.

[50] S. Han, J. K. Woo, Y. Jung et al., "Evodiamine selectively targets cancer stem-like cells through the p53-p21-Rb pathway," Biochemical and Biophysical Research Communications, vol. 469, p. 1153, 2016.

[51] M. Fritsch, S. D. Günther, R. Schwarzer et al., "Caspase-8 is the molecular switch for apoptosis, necroptosis and pyroptosis," Nature, vol. 575, p. 683, 2019.

[52] Y. Zhao, Q. Zhu, X. Bu et al., "Triggering apoptosis by oroxylin A through caspase-8 activation and p62/SQSTM1 proteolysis," Redox Biology, vol. 29, Article ID 101392, 2020.

[53] A. Boice and L. Bouchier-Hayes, "Targeting apoptotic caspases in cancer," Biochimica et Biophysica Acta (BBA)Molecular Cell Research, vol. 1867, Article ID 118688, 2020.

[54] M. Ma, X. Wang, N. Liu, F. Shan, and Y. Feng, "Low-dose naltrexone inhibits colorectal cancer progression and promotes apoptosis by increasing M1-type macrophages and activating the $\mathrm{Bax} / \mathrm{Bcl}-2 /$ caspase-3/PARP pathway," International Immunopharmacology, vol. 83, Article ID 106388, 2020.

[55] T. Zhang, G. Zhao, X. Zhu et al., "Sodium selenite induces apoptosis via ROS-mediated NF-kappaB signaling and activation of the Bax-caspase-9-caspase-3 axis in 4T1 cells," Journal of Cellular Physiology, vol. 234, pp. 2511-2522, 2019.

[56] M. Khan, Y. Bi, J. I. Qazi, L. Fan, and H. Gao, "Evodiamine sensitizes U87 glioblastoma cells to TRAIL via the death receptor pathway," Molecular Medicine Reports, vol. 11, p. $257,2015$.

[57] V. Mohan, R. Agarwal, and R. P. Singh, "A novel alkaloid, evodiamine causes nuclear localization of cytochrome-c and induces apoptosis independent of p53 in human lung cancer cells," Biochemical and Biophysical Research Communications, vol. 477, p. 1065, 2016.

[58] T. J. Lee, E. J. Kim, S. Kim et al., "Caspase-dependent and caspase-independent apoptosis induced by evodiamine in human leukemic U937 cells," Molecular Cancer Therapeutics, vol. 5, p. 2398, 2006.

[59] K. Sachita, Y. Kim, H. J. Yu, S. D. Cho, and J. S. Lee, "In vitro assessment of the anticancer potential of evodiamine in human oral cancer cell lines," Phytotherapy Research, vol. 29, p. 1145, 2015.

[60] C. Fang, J. Zhang, D. Qi et al., "Evodiamine induces G2/M arrest and apoptosis via mitochondrial and endoplasmic reticulum pathways in $\mathrm{H} 446$ and H1688 human small-cell lung cancer cells," PLoS One, vol. 9, Article ID e115204, 2014.

[61] A. J. Liu, S.-H. Wang, S.-Y. Hou et al., "Evodiamine induces transient receptor potential vanilloid-1-mediated protective autophagy in U87-MG astrocytes," Evidence-based Complementary and Alternative Medicine, vol. 2013, Article ID 354840, 9 pages, 2013.

[62] A. J. Liu, S.-H. Wang, K.-C. Chen et al., "Evodiamine, a plant alkaloid, induces calcium/JNK-mediated autophagy and calcium/mitochondria-mediated apoptosis in human glioblastoma cells," Chemico-Biological Interactions, vol. 205, p. 20, 2013.
[63] Z. Hong, Z. Wang, B. Zhou et al., "Effects of evodiamine on $\mathrm{PI} 3 \mathrm{~K} / \mathrm{Akt}$ and MAPK/ERK signaling pathways in pancreatic cancer cells," International Journal of Oncology, vol. 56, p. 783, 2020.

[64] Y. J. Tu, X. Fan, X. Yang, C. Zhang, and H. P. Liang, "Evodiamine activates autophagy as a cytoprotective response in murine Lewis lung carcinoma cells," Oncology Reports, vol. 29, p. 481, 2013.

[65] Y. Feng, D. He, Z. Yao, and D. J. Klionsky, "The machinery of macroautophagy," Cell Research, vol. 24, p. 24, 2014.

[66] C. Pohl and I. Dikic, "Cellular quality control by the ubiquitin-proteasome system and autophagy," Science, vol. 366, p. 818, 2019.

[67] X. Chen, C. Yu, R. Kang, G. Kroemer, and D. Tang, "Cellular degradation systems in ferroptosis," Cell Death \& Differentiation, vol. 28, p. 1135, 2021.

[68] M. C. Maiuri, E. Zalckvar, A. Kimchi, and G. Kroemer, "Selfeating and self-killing: crosstalk between autophagy and apoptosis," Nature Reviews Molecular Cell Biology, vol. 8, p. 741, 2007.

[69] G. Marino, M. Niso-Santano, E. H. Baehrecke, and G. Kroemer, "Self-consumption: the interplay of autophagy and apoptosis," Nature Reviews Molecular Cell Biology, vol. 15, p. 81, 2014.

[70] J. Zhuang, J. Yin, C. Xu, Y. Mu, and S. Lv, "20(S)-Ginsenoside Rh2 induce the apoptosis and autophagy in U937 and K562 cells," Nutrients, vol. 10, 2018.

[71] A. Thorburn, "Crosstalk between autophagy and apoptosis: mechanisms and therapeutic implications," Prog Mol Biol Transl Sci, vol. 172, p. 55, 2020.

[72] Y. Yan, S. Liu, M. Li et al., "Recombinant Newcastle disease virus expressing human IFN-lambda1 (rL-hIFN-lambda1)induced apoptosis of A549 cells is connected to endoplasmic reticulum stress pathways," Thoracic Cancer, vol. 9, p. 1437, 2018.

[73] C. de la Calle, P. E. Joubert, H. K. Law, M. Hasan, and M. L. Albert, "Simultaneous assessment of autophagy and apoptosis using multispectral imaging cytometry," Autophagy, vol. 7, p. 1045, 2011.

[74] L. Shi, F. Yang, F. Luo et al., "Evodiamine exerts anti-tumor effects against hepatocellular carcinoma through inhibiting beta-catenin-mediated angiogenesis," Tumor Biology, vol. 37, pp. 12791-12803, 2016.

[75] S. T. Hwang, J.-Y. Um, A. Chinnathambi et al., "Evodiamine mitigates cellular growth and promotes apoptosis by targeting the c-met pathway in prostate cancer cells," Molecules, vol. 25, 2020.

[76] P. Zhou, L. Xiao-Peng, J. Rong et al., "Evodiamine inhibits migration and invasion by Sirt1-mediated post-translational modulations in colorectal cancer," Anti-Cancer Drugs, vol. 30, p. 611, 2019.

[77] L. C. Zhao, J. Li, K. Liao et al., "Evodiamine induces apoptosis and inhibits migration of HCT-116 human colorectal cancer cells," International Journal of Molecular Sciences, vol. 16, pp. 27411-21, 2015.

[78] R. S. Apte, D. S. Chen, and N. Ferrara, "VEGF in signaling and disease: beyond discovery and development," Cell, vol. 176, p. 1248, 2019.

[79] W. H. Hu, G. K. Chan, R. Duan et al., "Synergy of ginkgetin and resveratrol in suppressing VEGF-induced angiogenesis: a therapy in treating colorectal cancer," Cancers (Basel), vol. 11, 2019.

[80] D. Aguilar-Cazares, R. Chavez-Dominguez, A. Carlos-Reyes, C. . Lopez-Camarillo, O. N. H. de la Cruz, and J. S. Lopez- 
Gonzalez, "Contribution of angiogenesis to inflammation and cancer," Frontiers in Oncology, vol. 9, p. 1399, 2019.

[81] M. Simons, E. Gordon, and L. Claesson-Welsh, "Mechanisms and regulation of endothelial VEGF receptor signalling," Nature Reviews Molecular Cell Biology, vol. 17, p. 611, 2016.

[82] X. Jin, X. Ge, D.-L. Zhu et al., "Expression and function of vascular endothelial growth factor receptors (Flt-1 and Flk-1) in vascular adventitial fibroblasts," Journal of Molecular and Cellular Cardiology, vol. 43, p. 292, 2007.

[83] H. Lee, A. J. Jeong, and S. K. Ye, "Highlighted STAT3 as a potential drug target for cancer therapy," BMB Reports, vol. 52, p. 415, 2019.

[84] A. Mantovani, "Molecular pathways linking inflammation and cancer," Current Molecular Medicine, vol. 10, p. 369, 2010.

[85] G. Gritsina, F. Xiao, S. W. O’Brien et al., "Targeted blockade of JAK/STAT3 signaling inhibits ovarian carcinoma growth," Molecular Cancer Therapeutics, vol. 14, p. 1035, 2015.

[86] H. Song, J. I. Jung, H. J. Cho et al., "Inhibition of tumor progression by oral piceatannol in mouse 4T1 mammary cancer is associated with decreased angiogenesis and macrophage infiltration," The Journal of Nutritional Biochemistry, vol. 26, pp. 1368-1378, 2015.

[87] K. Kessenbrock, V. Plaks, and Z. Werb, "Matrix metalloproteinases: regulators of the tumor microenvironment," Cell, vol. 141, p. 52, 2010.

[88] W. G. Jiang, A. J. Sanders, M. Katoh et al., “Tissue invasion and metastasis: molecular, biological and clinical perspectives," Seminars in Cancer Biology, vol. 35, pp. S244-S275, 2015.

[89] H. Huang, "Matrix metalloproteinase-9 (MMP-9) as a cancer biomarker and MMP-9 biosensors: recent advances," Sensors (Basel), vol. 18, 2018.

[90] S. Quintero-Fabian, R. Arreola, E. Becerril-Villanueva et al., "Role of matrix metalloproteinases in angiogenesis and cancer," Frontiers in Oncology, vol. 9, p. 1370, 2019.

[91] J. M. Chauvin and H. M. Zarour, "TIGIT in cancer immunotherapy," Journal for ImmunoTherapy of Cancer, vol. 8, 2020.

[92] B. Farhood, M. Najafi, and K. Mortezaee, "CD8(+) cytotoxic T lymphocytes in cancer immunotherapy: a review," Journal of Cellular Physiology, vol. 234, p. 8509, 2019.

[93] H. O. Alsaab, S. Sau, R. Alzhrani et al., "PD-1 and PD-L1 checkpoint signaling inhibition for cancer immunotherapy: mechanism, combinations, and clinical outcome," Frontiers in Pharmacology, vol. 8, p. 561, 2017.

[94] Z. B. Jiang, J.-M. Huang, Y.-J. Xie et al. "Evodiamine suppresses non-small cell lung cancer by elevating CD8(+) $\mathrm{T}$ cells and downregulating the MUC1-C/PD-L1 axis," Journal of Experimental \& Clinical Cancer Research, vol. 39, p. 249, 2020.

[95] Y. L. Li, Y.-N. Pan, W.-J. Wu et al., "Evodiamine induces apoptosis and enhances apoptotic effects of erlotinib in wildtype EGFR NSCLC cells via S6K1-mediated Mcl-1 inhibition," Medical Oncology, vol. 33, p. 16, 2016.

[96] X. Guan, X. Zheng, C. T. Vong et al., "Combined effects of berberine and evodiamine on colorectal cancer cells and cardiomyocytes in vitro," European Journal of Pharmacology, vol. 875, Article ID 173031, 2020.

[97] Q. Wu, Z. Yang, Y. Nie, Y. Shi, and D. Fan, "Multi-drug resistance in cancer chemotherapeutics: mechanisms and lab approaches," Cancer Letters, vol. 347, p. 159, 2014.
[98] I. A. Cree and P. Charlton, "Molecular chess? Hallmarks of anti-cancer drug resistance," BMC Cancer, vol. 17, p. 10, 2017.

[99] Y. G. Assaraf, A. Brozovic, A. C. Gonçalves et al., "The multifactorial nature of clinical multidrug resistance in cancer," Drug Resistance Updates, vol. 46, Article ID 100645, 2019.

[100] K. Bukowski, M. Kciuk, and R. Kontek, "Mechanisms of multidrug resistance in cancer chemotherapy," International Journal of Molecular Sciences, vol. 21, 2020.

[101] Z. L. Wang, L. Sun, H. Yu et al., "Binding mode prediction of evodiamine within vanilloid receptor TRPV1," International Journal of Molecular Sciences, vol. 13, p. 8959, 2012.

[102] G. Q. Dong, C. Sheng, S. Wang, Z. Miao, J. Yao, and W. Zhang, "Selection of evodiamine as a novel topoisomerase I inhibitor by structure-based virtual screening and hit optimization of evodiamine derivatives as antitumor agents," Journal of Medicinal Chemistry, vol. 53, pp. 7521-7531, 2010.

[103] W. F. Yang, L. Ma, S. Li, K. Cui, L. Lei, and Z. Ye, "Evaluation of the cardiotoxicity of evodiamine in vitro and in vivo," Molecules, vol. 22, p. 943, 2017. 